\title{
Use of the Appropriate Fabric for Cloth Face Mask: A Necessity in the Fight against COVID-19
}

\author{
Richard Selase Gbadegbe*, Edem Kwami Buami, Charles Kumah, Divine Vigbedor \\ Department of Industrial Art, Ho Technical University, Ho, Ghana \\ Email: *rgbadegbe@htu.edu.gh, ebuami@htu.edu.gh, ckumah@htu.edu.gh,dvigbedor@htu.edu.gh
}

How to cite this paper: Gbadegbe, R.S., Buami, E.K., Kumah, C. and Vigbedor, D. (2021) Use of the Appropriate Fabric for Cloth Face Mask: A Necessity in the Fight against COVID-19. Journal of Textile Science and Technology, 7, 172-187.

https://doi.org/10.4236/jtst.2021.74015

Received: September 27, 2021

Accepted: November 20, 2021

Published: November 23, 2021

Copyright $\odot 2021$ by author(s) and Scientific Research Publishing Inc. This work is licensed under the Creative Commons Attribution International License (CC BY 4.0).

http://creativecommons.org/licenses/by/4.0/

\begin{abstract}
The outbreak of coronavirus disease (COVID-19) has created a global health crisis that has had a deep impact on the way we perceive our world and our everyday lives. The call for the wearing of face masks as one of the ways of curbing the disease has resulted in the proliferation of cloth face masks on our markets. In the desperation to cash in on the season and make money at all costs, some manufacturers use inferior fabrics to produce face masks. Some of these fabrics do not meet the basic performance requirements of cloth face masks. This study was therefore carried out to research into the appropriate fabrics that will be suitable for the production of cloth face masks in terms of comfort, breathability and protection. To do this, 1225 participants were conveniently drawn for the study. The main research instrument employed for the study was the survey approach in which well-structured questionnaires were administered to solicit information from the participants. To determine the reliability and validity of data, the Cronbach's Alpha test was conducted. Data were analyzed using the Stata statistical software to perform a multinomial logistic regression to estimate Odds Ratios (ORs) with 95\% CIs. A multinomial logit model was constructed to determine the nominal variables. A major finding of the study was that people's choice of fabric for cloth face masks is determined to a larger extent by their professions. The study also revealed that cotton, silk and linen possess good properties for the production of cloth face masks. Based on the findings, the study concludes that cloth face masks made from two-layered fabrics or three-layered fabrics are the best in terms of comfort and full protection of the wearer. It is recommended that the outer layer should be made from cotton and the inner layer made from linen, cotton-polyester blend or silk.
\end{abstract}

\section{Keywords}

Air Permeability, Breathability, COVID-19, Fabric, Cloth Face Mask 


\section{Introduction}

COVID-19 is described as an illness caused by a novel virus called coronavirus which was outbroken in Wuhan City, Hubei Province, China on December 31, 2019 and declared as a global health emergency on January 30, 2020, finally as a pandemic by WHO on March 11, 2020 [1]. It is a respiratory illness which has rapidly spread globally with confirmed death cases of 4,570,946 as of September 2021 (WHO, Website). Based on the WHO recommendations, almost all countries have adopted stringent measures to curb the spread of the COVID-19 disease. These include lockdowns, restriction of travel distances, the use of face masks, observation of social distance, usage of hand sanitizers, regular hand washing with soap, and limitation of the number of participants at social gatherings [2]. All the preventive measures implemented globally to curb the spread of the COVID-19 disease involved behavioral changes from the people [3].

Among WHO's Personal Protective Equipment (PPEs) for the prevention of the spread of COVID-19 is the use of face masks. According to the Department of Public Health in San Francisco [4], face masks are loose-fitting masks that cover the nose and mouth, and have ear loops or ties or bands at the back of the head. There are generally three types of face masks. These are homemade cloth face masks, surgical masks and N95 respirators with their main aim being prevention of inhalation of microorganisms and smaller particulate matter through the mouth and throat cavities [5]. Surgical masks are disposable, loose-fitting face masks that cover the nose, mouth, and chin. They are typically used to protect the wearer from sprays, splashes, and large-particle droplets.

According to [6], locally manufactured textiles or cloth masks lately have become popular choices, particularly in the developing world due to easy accessibility and affordability. The COVID-19 pandemic has taught citizens from developing countries the necessity to mask up and this has caused the youth most especially to adopt the sense of creativity by manufacturing various brands of cloth masks. [7] stressed that cloth face masks can be made at home from common materials. Thus, they are in abundance and may lower the risk of people contracting diseases without symptoms, transmitting the microorganisms such as viruses through speaking, coughing, or sneezing. With regard to prevention of the COVID-19 disease, [8] stated that the homemade face masks are better than not using any masks and offer some level of protection, especially where social distancing is hard to maintain compared to surgical masks or N95 respirators.

The World Health Organization (WHO) has recommended for public use homemade face masks from fabrics especially in developing countries where people cannot afford surgical masks or N95 respirators which are not recyclable [9]. In addition, homemade face masks are simple to make by any seamstress or tailor from any available fabric [10]. Thus, the production and usage of homemade masks are preventive measures to help limit transmission of the COVID-19 virus among poor rural community members especially citizens who cannot afford the relatively expensive surgical masks or N95 respirators. Furthermore, homemade masks are 
easily washable and can be reused for several weeks. Therefore, its patronage is being encouraged [11].

According to Trade Industry \& Competition, of the Republic of South Africa [12], one important factor to consider in the design and manufacture of homemade face masks is the quality of the fabric. The World Health Organization (WHO) states that the following parameters are very necessary to be considered when selecting fabrics for homemade face masks. They include the basic performance requirements, the fabric selection impacting, comfort, design for optimal functionality, disposal, safety, disinfection among others. [13] advised that fabrics used for the manufacture of face masks must be carefully selected in order to prevent re-infestation and to ensure that the wearer feels comfortable. There must be an inner layer to provide a smooth, soft, pleasant feel against the skin [14]. Also, the fabric should not irritate the skin in any way or allow the build-up of moisture or excessive heat in between the skin and the mask. Water repellent fabrics that inhibit the absorption of droplets must be avoided [15]. It must not wet easily or accumulate excessive moisture with breathing. [16] revealed that the fabric should have very high air permeability and should not restrict normal breathing. Synthetic fibres are recommended for quick-drying properties. If cotton, poly-cotton or viscose is used, care should be taken as these fabrics can be highly water absorbent and might become wet against the skin. They can also impact heat generation, potential fibre/fluff shedding and drying time after washing [17].

The design and manufacture of homemade face masks can be a combination of different types of fabrics for optimal use. For instance, according to the American Chemical Society [18], a combination of cotton with natural silk or chiffon can effectively filter out aerosol particles and thus a good fit for homemade masks. It is also recommended that fabrics used for face masks should be free from all chemicals [19]. In any event that printed fabric is used; the layer of the fabric in direct contact with the face should be plain fabric that is free from chemicals.

In Ghana, the FDA recommends that a fabric that qualifies for an effective homemade face mask must generally be able to filter out particles and still be easily breathed through. In the absence of propylene, which is the commonest material used for medical-grade face masks, $100 \%$ cotton or cotton blend materials possess good characteristics to use as fabrics for homemade face masks [15]. Recent studies and evaluations undertaken by the FDA in Ghana indicated that viable fabrics for the production of effective homemade face masks include: 1) calico-stiff (medium)-Calico; and 2) calico-calico-calico; all designed as a 3 layer combination which is ideal for a reusable homemade COVID-19 face mask. However, the researchers observed that people often use homemade face masks made from other fabric types aside from the recommended ones from the FDA. In addition, people design and manufacture homemade face masks from pieces of fabrics used to sew their various cloths/garments to match up in a fashionable manner. To the best of the researchers' knowledge, no empirical study was conducted 
in Ghana to determine the suitability of various fabrics used in the manufacture of homemade face masks. Thus, this study focuses on exploring various factors that influence the selection of fabrics for the manufacturing of homemade face masks in Ghana.

\section{Methodology}

\subsection{Population and Sampling}

The study was conducted across all the 16 regions in Ghana. According to the Ghana Statistical Service [20], the population of Ghana was estimated to be about $31,072,940$ as at December 2020. The target population for the study was any person who used homemade face masks in the COVID-19 era. The theoretical sample size for the study was determined to be 3,418,914 using the online sample size calculator based on the aforementioned population of Ghana. The participants who responded to the questionnaires distributed through social media, email and whatsApp platforms were 1225. The number was less than the actual theoretical sample size because of unwillingness of some participants to be part of the study.

\subsection{Data Collection Instrument}

The data collection instrument used in this study was a structured questionnaire. The questionnaire was developed into various sections where both closed and open-ended questions were asked to solicit information from the participants. Seven (7) different fiber types which were used in the manufacture of homemade face masks were considered in this study. They include Cotton, Wool, Polyester, Linen, Silk, Nylon, and Polythene. These fibers were later categorized into Cellulosic, Protein and Synthetic fibers for easy analysis. The questions were based on the above parameters and participants' views were sought on which of the following factors; breathability, comfort ability, feel and cost of fabric influence their choice of mask type. The questionnaire was pre-tested or piloted to detect any ambiguity and the duration for responding to the questionnaire. Suggestions from respondents were incorporated into the final questionnaire which was later developed into a Google form questionnaire and distributed online to various respondents.

\section{Data Analysis}

The data collected was edited, coded and entered into Statistical Package for Social Scientists (SPSS) version 22 software. Reliability analysis test was determined using Cronbach's alpha test. Analysis of Variance (ANOVA) of the mean values obtained for each fabric type was carried out. Furthermore, Least Significance Difference (LSD) was also carried out. Finally, multinomial logistic regression was performed to estimate whether people's choice of fabric for face mask might be influenced by their own profession. The researchers believed that using more than one data analysis approach would enhance the quality and validity of the study 
by combining and integrating the strengths associated with each method.

\section{Results and Discussion}

\subsection{Reliability Test}

To determine the degree of consistency for the set of variables or scale of measurement, a reliability test was conducted. The reliability test checked the consistency or whether the variables composing the scale were correlated with each other. In this study, the internal consistency reliability was employed to measure the reliability of the research instrument. Internal consistency reliability was used to assess the consistency of the results from the variables within the test. For the purpose of this study, the Cronbach alpha test was employed.

\section{Cronbach's Alpha Test $(\alpha)$}

Cronbach's alpha test $(\alpha)$ measures the correlation among the variables of a scale. It is the most common measure of reliability (consistency) of a scale. The higher the correlation among the variables of the scale is, the more consistent the research instrument. In general, the accepted Cronbach alpha value is 0.7 and above, while a reliability coefficient of 0.6 is acceptable for exploratory research. In this study, the Cronbach alpha reliability test $(\alpha)$ of the scales was 0.778 . The test results (indicated that there are high correlation among the variables of the scale for Cotton, Linen, Wool, Silk, Polyester, Nylon and Polythene (Table 1). This implies that questions asked in this study are reliable and valid to address the objectives.

\subsection{Demographic Characteristics of Respondents}

The demographic characteristics of respondents for the study are presented in Table 2. The gender distribution of the study shows that, most of the respondents (64.2\%) were females while the rest (35.8\%) were males. This suggests that more females are enthused about the wearing of homemade face masks than the males. This could also be attributed to female attitude of accepting things easily

Table 1. Cronbach's alpha test ( $\alpha$ ) reliability test for fiber types.

\begin{tabular}{cc}
\hline Type of Fiber & Cronbach's Alpha Test $(\boldsymbol{\alpha})$ \\
\hline Cotton & 0.789 \\
Linen & 0.710 \\
Wool & 0.723 \\
Silk & 0.760 \\
Polyester & 0.701 \\
Nylon & 0.756 \\
Polythene & 0.710
\end{tabular}


Table 2. Demographic Characteristics of respondents.

\begin{tabular}{ccc}
\hline Characteristics & Frequency & Percentage \\
\hline Male & Gender & \\
Female & 739 & 35.8 \\
\hline & Age (years) & 64.2 \\
\hline $15-25$ & 265 & 21.6 \\
$26-30$ & 562 & 45.9 \\
$31-40$ & 328 & 26.8 \\
41 and above & 70 & 5.7 \\
& 181 & 14.8 \\
\hline Primary-junior high school & 599 & 48.9 \\
Senior high school & 445 & 36.3 \\
Tertiary & Educational level & \\
\hline Formal & Occupation of respondents & 57.8 \\
Informal & 708 & 42.2 \\
\hline
\end{tabular}

than males who are more rigid and want more prove. The age distribution indicates that, most of the respondents (45.9\%) fell within the age range of 26 to 30 years while $26.8 \%$ of the respondents fell within the age range of $31-40$ years. This implies that majority of the respondents who participated in the study belonged to the youthful age. Majority of the respondents (48.9\%) had up to Senior Secondary School educational level and were working in the formal sector (57.8\%). This shows that the participants are educated and have enough knowledge about the COVID-19 pandemic and the preventive protocols including wearing of face mask.

\subsection{Comparison of Fiber Properties}

\subsubsection{Cellulosic Fibers}

Cotton and Linen are classified as cellulosic fibers. They have their base from cellulose which is a fibrous material of plant origin and the basis of all natural and man-made cellulosic fibers [21]. The results from the study show that (57.4\%) of the respondents highly recommended Cotton to be very comfortable when used as homemade face mask (Table 3 ). Only $14.9 \%$ of respondents highly recommended the comfort ability of Linen fabric usage as homemade face mask. Comparatively, Cotton is recommended by all respondents to be comfortable than Linen. This is because Cotton is extremely breathable and absorbent, as it can absorb up to $25 \%$ of its weight in moisture as compared to Linen [22]. This is in tandem with Dipanwita's result which states that $100 \%$ cotton fabric with a high thread count has high breathability and is the most preferred and commonly used fabric for a cloth facemask [23]. Furthermore, 53.8\% of the respondents 
Table 3. Comparison of fiber properties of cotton and linen.

\begin{tabular}{ccccccc}
\hline \multirow{2}{*}{ Fabric properties } & \multicolumn{3}{c}{ Cotton (\% of response) } & \multicolumn{3}{c}{ Linen (\% of response) } \\
\cline { 2 - 7 } & HR & R & NR & HR & R & NR \\
\hline Very comfortable & 57.4 & 42.6 & 0.0 & 14.9 & 48.0 & 37.1 \\
Able to breathe well & 46.2 & 53.8 & 0.0 & 33.1 & 48.2 & 18.6 \\
Feels soft to wear & 57.8 & 42.2 & 0.0 & 48.2 & 40.7 & 11.1 \\
Smells good to wear & 53.9 & 0.0 & 46.1 & 37.2 & 18.4 & 44.3 \\
$\quad$ Expensive & 61.7 & 15.3 & 22.9 & 37.0 & 48.2 & 14.8 \\
Available & 50.0 & 11.5 & 38.5 & 44.4 & 22.3 & 33.3 \\
Easy to sew & 69.4 & 30.6 & 0 & 44.3 & 18.6 & 37.1 \\
\hline
\end{tabular}

HR: Highly Recommended; R: Recommended; NR: Not Recommended.

recommended that they can easily breathe well through homemade face masks made from Cotton compared to that of Linen (48.2\%). The results further indicated that $57.8 \%$ of the respondents were of the opinion that Cotton fabric feels soft in wearing than Linen (48.2\%). Therefore, it was highly recommended than Linen. Similarly, $53.9 \%$ of the respondents highly recommend Cotton as a fabric which smells good to wear when used to sew homemade face mask relative to linen (37.2\%). According to majority of respondents (61.7\%), Cotton fabric is more expensive but readily available (50.0\%) and easy to sew (69.4\%) as a homemade face mask than Linen. Comparatively, Cotton possesses good properties for the production of homemade face mask than Linen.

\subsubsection{Protein Fibers}

Table 4 presents test results obtained after comparing the fabric properties of Wool and Silk fibers, collectively known as protein fibers. Protein fibers also known as animal fibers are naturally occurring fibers that are sourced from animals, as the name suggests. They are made up of different types of proteins in general. Some of the most common animal fibers are Wool and Silk [24]. Despite the fact that Wool and Silk are both obtained from animal sources, they have distinctive chemical and physical properties which make them unique. In Table 4 below, only $18.4 \%$ of the respondents who participated in the study highly recommended Wool as very comfortable for the production of face mask while $14.8 \%$ of the respondents highly recommended Silk as a very comfortable fiber for the production of face mask. As high as $48.3 \%$ of the respondents did not recommend Wool as a very comfortable fabric for the production of face mask while $48.2 \%$ of the respondents were unable to recommend Silk as a very comfortable fabric for face mask. Meanwhile only $14.7 \%$ of the respondents highly recommended the breathability of Wool for the manufacture of face mask. Additionally, $22.1 \%$ of respondents highly recommended the breathability of Silk for the production of face mask. The soft feel properties of Wool and Silk 
Table 4. Comparison of fiber properties of wool and silk.

\begin{tabular}{ccccccc}
\hline \multirow{2}{*}{ Fabric properties } & \multicolumn{3}{c}{ Wool (\% of response) } & \multicolumn{3}{c}{ Silk (\% of response) } \\
\cline { 2 - 7 } & HR & R & NR & HR & R & NR \\
\hline Very comfortable & 18.4 & 33.3 & 48.3 & 14.8 & 37.1 & 48.2 \\
Able to breathe well & 14.7 & 44.5 & 40.8 & 22.1 & 26.0 & 51.9 \\
Feels soft to wear & 62.9 & 22.2 & 14.9 & 55.6 & 29.6 & 14.9 \\
Smells good to wear & 22.0 & 40.8 & 37.1 & 36.9 & 15.0 & 48.1 \\
Expensive & 25.8 & 51.9 & 22.3 & 33.1 & 37.2 & 29.7 \\
Available & 40.8 & 29.1 & 30.0 & 40.8 & 44.4 & 14.8 \\
Easy to sew & 11.1 & 40.7 & 48.2 & 26.0 & 26.0 & 48.1 \\
\hline
\end{tabular}

HR: Highly Recommended; R: Recommended; NR: Not Recommended.

were highly recommended by respondents. $62.9 \%$ of the respondents highly recommended the soft feel of wool while $55.6 \%$ of respondents highly recommended the soft feel of Silk for the production of face mask. Just $22.0 \%$ of the respondents highly recommended that Wool smells well when worn as a face mask. On the other hand, $36.9 \%$ of respondents highly recommended Silk as a fabric that smells well when worn as a face mask. Also, $25.8 \%$ of respondents and $33.1 \%$ of the respondents highly recommended Wool and Silk respectively as expensive fabrics for the manufacture of face mask. $40.8 \%$ of respondents for both Wool and Silk stated that Wool is readily available for the production of face mask. $26.0 \%$ of respondents stated that Silk can easily be sewn than Wool (11.1\%) for the production of face mask. Comparatively, Silk possesses good properties for the production of homemade face mask than Wool.

Table 5 shows the results obtained from respondents on the properties of some selected synthetic fibers for the production of face mask. The synthetic fibers considered were: Polyester, Nylon and Polythene. Synthetic fibers are a class of fibers produced from chemical substances mostly petro chemicals. It can be observed from the test results that the comfort ability of synthetic fibers for the production of face mask has been mostly rated low: $16.2 \%$ for Polyester, $3.8 \%$ for Nylon and 3.7\% for Polythene (Table 5). This is true because synthetic fibers are highly crystalline. Their molecules are closely packed and do not allow smooth air flow. About $44 \%$ of respondents recommended Polyester as the most breathable synthetic fiber for the production of face mask. This result was confirmed by [25] which suggests that the most effective fabric for cloth face mask for breathability and filtering out particles is Polyester. The ability of wearers to be able to breathe well when wearing face masks made of synthetic fiber has also been rated low. The lowest among them is Polythene which was rated by $7.3 \%$ of the respondents. However the soft feel of the synthetic fibers was highly rated by respondents. As high as $62.4 \%$ of the respondents highly recommended Polyester as a fabric that feels soft when worn as a face mask, $66.7 \%$ of the respondents highly recommended Nylon as a fabric with a soft feel while $59.3 \%$ highly recommended Polythene as a soft material for the production of face mask. The 
Table 5. Comparison of fiber properties polyester, nylon and polythene.

\begin{tabular}{|c|c|c|c|c|c|c|c|c|c|}
\hline \multirow{2}{*}{$\begin{array}{c}\text { Fabric } \\
\text { properties }\end{array}$} & \multicolumn{3}{|c|}{$\begin{array}{c}\text { Polyester } \\
\text { (\% of response) }\end{array}$} & \multicolumn{3}{|c|}{$\begin{array}{c}\text { Nylon } \\
\text { (\% of response) }\end{array}$} & \multicolumn{3}{|c|}{$\begin{array}{c}\text { Polythene } \\
\text { (\% of response) }\end{array}$} \\
\hline & HR & $\mathbf{R}$ & NR & HR & $\mathbf{R}$ & NR & HR & $\mathbf{R}$ & NR \\
\hline $\begin{array}{c}\text { Very } \\
\text { comfortable }\end{array}$ & 16.4 & 34.8 & 48.8 & 3.8 & 29.6 & 66.5 & 3.7 & 18.6 & 77.7 \\
\hline $\begin{array}{l}\text { Able to breathe } \\
\text { well }\end{array}$ & 16.2 & 44.0 & 39.8 & 15.0 & 33.2 & 51.8 & 7.3 & 29.7 & 62.9 \\
\hline $\begin{array}{l}\text { Feels soft } \\
\text { to wear }\end{array}$ & 62.4 & 22.7 & 14.9 & 66.7 & 14.8 & 18.5 & 59.3 & 26.0 & 14.7 \\
\hline $\begin{array}{l}\text { Smells good } \\
\text { to wear }\end{array}$ & 23.5 & 37.4 & 39.1 & 15.0 & 25.9 & 59.1 & 3.7 & 55.4 & 40.9 \\
\hline Expensive & 28.2 & 49.0 & 22.8 & 7.5 & 63.0 & 29.5 & 26.0 & 48.1 & 26.0 \\
\hline Available & 36.9 & 26.5 & 36.6 & 26.0 & 11.2 & 62.9 & 11.1 & 7.3 & 81.6 \\
\hline Easy to sew & 15.0 & 41.1 & 43.8 & 29.7 & 48.2 & 22.1 & 29.7 & 51.8 & 18.4 \\
\hline
\end{tabular}

HR: Highly Recommended; R: Recommended; NR: Not Recommended.

good smell of the synthetic fibers was rated low by respondents. The lowest among them is Polythene rated by $3.7 \%$ of the respondents. Furthermore synthetic fibers were rated as not being expensive. Only $7.5 \%$ of the respondents highly recommended Nylon as an expensive fabric. The rest were rated as follows: $28.2 \%$ for Polyester and 26.0 for Polythene. As far as the availability of the fabrics is concerned, Polyester is the most highly rated with $36.9 \%$. The low rated fiber among the three synthetic fibers for the ability to be easily sewn is Polyester $15.0 \%$. Comparatively, among the 3 synthetic fibers assessed, Polyester possesses good properties for the production of home-mad face mask.

\subsection{Comparison of Fiber Types}

The seven (7) fiber types studied were compared in relation to their fabric properties. The ANOVA shows significant difference $(\mathrm{p}<0.05)$ between the fiber types regarding comfort ability of wearing homemade face masks. However, Least Significance Difference (LSD) analysis shows that wearing of face mask made of Cotton is more comfortable compared to other types of fabrics (Table 6). This is attributed to tiny holes in the Cotton fabric which ensure maximum better breathability, protection and prevention of infection to the wearer [26]. Significant differences $(p<0.05)$ were also observed for Wool and Linen, Nylon and Polythene due to differences in physical and chemical properties of the fiber types. Furthermore, no significant differences were observed for comfort ability of wearing face mask made from Wool and Polyester and Silk $(p>0.05)$ due to similarities in properties of the three fibers. Face masks made from Silk and Polyester did not show significant difference ( $p=0.708)$ in terms of comfort ability for wearing because they are both filament fibers comprising long and continuous fiber strands. 
Table 6. Comparison of mean values of fiber types.

\begin{tabular}{cccccccccc}
\hline \multirow{2}{*}{$\begin{array}{c}\text { Fabric } \\
\text { Properties }\end{array}$} & \multicolumn{8}{c}{ Mean Responses } \\
\cline { 2 - 9 } & Cotton & Wool & Polyester Linen & Silk & Nylon & Polythene & P Value \\
\hline & 2.57 & 1.70 & 1.68 & 1.78 & 1.67 & 1.37 & 1.26 & 0.00 \\
Breathability & 2.46 & 1.74 & 1.76 & 2.15 & 1.70 & 1.63 & 1.44 & 0.00 \\
Feel/Handle & 2.58 & 2.48 & 2.47 & 2.37 & 2.41 & 2.48 & 2.45 & 0.00 \\
Scent/Smell & 2.08 & 1.85 & 1.84 & 1.93 & 1.89 & 1.56 & 1.63 & 0.00 \\
$\begin{array}{c}\text { Cost of Material } \\
\text { Availability of }\end{array}$ & 2.39 & 2.04 & 2.06 & 2.22 & 2.03 & 1.78 & 2.00 & 0.00 \\
Material & 2.11 & 2.11 & 2.00 & 2.11 & 2.26 & 1.63 & 1.29 & 0.00 \\
Sewability & 2.69 & 1.63 & 1.71 & 2.07 & 1.778 & 2.08 & 2.11 & 0.00 \\
\hline
\end{tabular}

There was a marked significant difference $(\mathrm{p}<0.05)$ in the breathability of wearing face masks made from different fabrics. The Least Significance Difference (LSD) analysis shows that face masks made of Cotton and Linen are more breathable than the other types of fabrics. This is clearly because of the orientation of the molecules in both fibers. Additionally, face masks made from Wool, Nylon and Polythene show significant differences $(p<0.05)$ as far as breathability is concerned. The reason is that the fiber orientations for Nylon and Polythene are highly crystalline while the fiber orientation for Wool is full of amorphous regions which make the fabric very airy. However, face masks made from Silk and Wool did not show any significant differences for breathability $(\mathrm{p}=0.187)$. This could be due to the fact that both Silk and Wool fibers are protein fibers with similar chemical properties.

There was a significant difference $(\mathrm{p}<0.05)$ as far as the feel/handle of face masks made out of different fabric types are concerned. However, Least Significance Difference (LSD) analysis shows that face masks made from Cotton have a better feel/handle as compared to other types of fabrics. It can be observed from the results that face masks made from Nylon and Cotton, Polyester and Cotton showed some significant differences $(\mathrm{p}<0.05)$ in their feel/handle. This could be due to the fact that Nylon and Polyester are both synthetic fibers, having similar fiber orientation and texture while Cotton is a natural fiber, having a smooth feel/handle. Additionally, face masks made from Linen, Wool and Polyester also showed some significant differences $(\mathrm{p}<0.05)$ in the feel/handle of the fabric. However, the results indicated that face masks made from Polyester, Nylon and Polythene did not show any significant differences $(p>0.05)$. The reason is that Polyester, Nylon and Polythene are all synthetic fibers which have almost the same fiber properties. Furthermore, the results showed that there were no significant differences in the feel/handle of face masks made from Silk, Wool and Linen. This could be due to the fact that all the three fibers are natural fibers, having similar physical properties.

There was a significant difference $(\mathrm{p}<0.05)$ in the scent/smell of wearing face 
mask made from different fabrics. However, Least Significance Difference (LSD) analysis shows that the wearing of face mask made of Cotton has a more appealing scent/smell as compared to other types of fabrics. In addition, the results indicated that fabrics made from Wool, Linen and Nylon showed significant differences in their scent/smell when worn by the wearer. This can be explained in the fact that Wool, Linen and Nylon are three different fibers which have different levels of scent tolerance. The results further recorded significant differences in the scent/smell of Silk and Polythene which points to the fact that the two fibers have different levels of scent/smell tolerance. Meanwhile the results indicated that Wool and Silk as well as Linen and Silk did not show significant differences in their scent/smell. This is expected because Wool and Silk are both protein fibers which have similar levels of scent tolerance. Linen and Silk on the other hand have similar fiber orientations as natural fibers. [27] agreed that the fiber composition, or fiber content, of fabrics affects their properties and their suitability for use in masks.

There was a significant difference $(\mathrm{p}<0.05)$ in the sewability of face masks made of different fabrics. The Least Significance Difference (LSD) analysis shows that face masks made from Wool, Cotton, Silk and Linen are more sewable than other type of fabric. This could be due to the fact that Cotton, Silk and Linen are all natural fibers which possess similar physical properties. However, it was observed that face masks made from Nylon, Polythene, and Polyester did not show significant differences as far as sewability is concerned $(p>0.05)$. The reason for this result could be due to the fact that Nylon, Polythene and Polyester are synthetic fibers which have related physical properties.

\subsection{Regression Analysis}

To determine the relationship between the demographic characteristics and choice of fiber types, a multinomial logistic regression was carried out (Table 7). The outcome variable was classified into three categories such as office holder, academic and vocation. The multinomial logistic regression was performed to estimate odds ratios (ORs) with $95 \%$ Cis. Vocation was used as a reference category (Table 7). This means, the comparison will be against people in vocation as their profession. The Variance Inflation Factor (VIF) was calculated to assess multicollinearity in the logistic regression model. Stata statistical software was used for all data analysis.

\subsubsection{Office Holders}

The use of Wool, Polyester, Linen and Silk for face mask had a significant ( $\mathrm{p}<$ 0.05 ) contribution to the explanation of office holders' choice of fabric for face mask. This implies that the respondents within the office holders' category as compared to those in a vocation are more likely to use face masks made from Wool, Polyester, Linen and Silk. Moreover, the coefficients as against vocation indicate that office holders are less likely to use face masks made from Cotton, Nylon and Polythene fabrics. Also, the relative log odds of being an office holder 
Table 7. People's choice of fabric for face mask might be influenced by their own profession.

\begin{tabular}{|c|c|c|c|c|c|c|c|c|c|c|}
\hline \multirow{2}{*}{ Variables } & \multicolumn{5}{|c|}{ Office Holders } & \multicolumn{5}{|c|}{ Academic } \\
\hline & B & Std. Error & Wald & Sig. & $\operatorname{Exp}(B)$ & B & Std. Error & Wald & Sig. & $\operatorname{Exp}(B)$ \\
\hline Intercept & -0.212 & 1.537 & 0.019 & 0.890 & & -4.690 & 1.478 & 10.071 & 0.002 & \\
\hline Cotton & -0.018 & 0.017 & 1.230 & 0.267 & 0.981 & 0.036 & 0.017 & 4.550 & 0.033 & 1.037 \\
\hline Wool & 0.019 & 0.018 & 1.786 & 0.181 & 1.025 & 0.049 & 0.018 & 7.859 & 0.005 & 1.051 \\
\hline Polyester & 0.023 & 0.020 & 1.010 & 0.315 & 1.020 & 0.112 & 0.020 & 32.583 & 0.000 & 1.119 \\
\hline Linen & 0.046 & 0.017 & 5.214 & 0.022 & 1.039 & -0.066 & 0.017 & 15.860 & 0.000 & 0.936 \\
\hline Silk & 0.054 & 0.014 & 8.023 & 0.005 & 1.040 & 0.072 & 0.014 & 25.212 & 0.000 & 1.075 \\
\hline Nylon & -0.073 & 0.028 & 3.432 & 0.064 & 0.949 & -0.091 & 0.028 & 10.883 & 0.001 & 0.913 \\
\hline Polythene & -0.091 & 0.031 & 8.449 & 0.004 & 0.914 & -0.081 & 0.030 & 7.316 & 0.007 & 0.922 \\
\hline Age $=2$ & 0.276 & 0.256 & 1.08 & 0.280 & 0.944 & 0.347 & 0.394 & 0.776 & 0.378 & 1.415 \\
\hline Age $=3$ & 0.014 & 0.404 & 0.088 & 0.767 & 1.126 & 0.291 & 0.405 & 0.516 & 0.473 & 1.337 \\
\hline Ses $=2$ & -1.44 & 0.286 & & & & & & & & \\
\hline \multicolumn{11}{|l|}{ Ses $=3$} \\
\hline \multicolumn{11}{|l|}{2} \\
\hline \multicolumn{11}{|l|}{3} \\
\hline Gender & 0.331 & 0.266 & 0.838 & 0.360 & 1.276 & 0.505 & 0.254 & 3.950 & 0.047 & 1.656 \\
\hline Occupation & -0.893 & 0.311 & 8.261 & 0.004 & 0.409 & -0.504 & 0.316 & 2.546 & 0.111 & 0.604 \\
\hline
\end{tabular}

as opposed to vocation will decrease 0.014 if moving from the lowest level of SES to the highest level of SES. However, the relative log odds of being an office holder as compared to vocation will increase 0.276 if moving from the lowest level of SES to the medium level of SES.

\subsubsection{Academics}

The use of Cotton, Wool, Polyester and Silk for face mask had a significant ( $\mathrm{p}<$ 0.05) contribution to explanation of academic's choice of fabric. This indicates that, people in academia as against those in a vocation are more likely to use face masks made from Cotton, Wool, Polyester and Silk. On the other hand, the coefficients of academics as against vocation indicate that academics are less likely to use face masks made from Linen, Nylon and Polythene fabrics. The relative log odds of being an academic as opposed to vocation will decrease 0.169 if moving from the lowest level of SES to the highest level of SES. However, the relative log odds of being an academic as opposed to vocation will increase 0.068 if moving from the lowest level of SES to the medium level of SES.

\subsection{Multinomial Logit Model}

The multinomial Logit is used for nominal or ordered variables where the variables are not in ordering. Some researchers have used multinomial logit to model visitors' decision making system [28], firm strategy [29] and travel choice 
behaviour. In multinomial logit model there is one set of parameters for each category of $Y$. The probabilities of the different outcomes of $Y$ are expressed as:

$$
P_{r}(Y=j / X)=\frac{\exp \left(X \beta_{j}\right)}{\sum_{l=1}^{J} \exp \left(X \beta_{l}\right)}
$$

where $\beta$ set to zero for one of the outcomes. The outcome for which the $\beta$ vector is set to zero is called the "base outcome" or the "reference category". The parameter estimates of the multinomial Logit therefore express differences compared to the base outcome. The odds of outcome $j$ versus outcome $k$ are expressed as follows:

$$
\begin{gathered}
\frac{P_{r}(Y=j / X)}{P_{r}(Y=k / X)}=\frac{P_{j}}{P_{k}} \\
\frac{\exp \left(X \beta_{j}\right)}{\sum_{l=1}^{j} \exp \left(X \beta_{l}\right)} \div \frac{\exp \left(X \beta_{k}\right)}{\sum_{l=1}^{J} \exp \left(X \beta_{l}\right)} \\
\frac{\exp \left(X \beta_{J}\right)}{\exp \left(X \beta_{k}\right)}
\end{gathered}
$$

Taking the logarithm yields:

$$
\ln \left(P_{j} / P_{k}\right)=X\left(\beta_{j}-\beta_{k}\right)
$$

Multinomial logit model can best be used when the choice consists of more than two alternatives dependent variables. For instance, when there are three choices such as: low, medium and high. The dependent variable $Y$ represents the three values: $Y_{a}=1$ means low, $Y_{b}=2$ means medium and $Y_{c}=3$ stand for high. In this type of model, two logit function are required therefore, $Y_{c}=3$ has to use as the baseline outcome to form logits which $Y_{a}=1$ and $Y_{b}=2$ can be compared to. The two logit functions can be stated as follows:

$$
\begin{aligned}
& \operatorname{logit}\left(P_{1}\right)=\ln \left(\frac{P\left(Y_{a}=1 / X\right)}{P\left(Y_{c}=3 / X\right)}\right)=\alpha_{1}+\sum_{i=1}^{n} \beta_{1_{i}} X_{i} \\
& \operatorname{logit}\left(P_{2}\right)=\ln \left(\frac{P\left(Y_{b}=2 / X\right)}{P\left(Y_{c}=3 / X\right)}\right)=\alpha_{2}+\sum_{i=1}^{n} \beta_{2_{i}} X_{i}
\end{aligned}
$$

where $X_{i}$ is the value of the $i$ th independent variable, $\alpha_{1}$ is the intercept of the first logit function, $\alpha_{2}$ is the intercept of the second logit function, $\beta_{1_{i}}$ is the corresponding coefficient in the number of variables.

\section{Conclusions}

In conclusion, the study which sought to determine the appropriate fabric for cloth face mask has revealed that for a fabric to be considered as appropriate for the production of cloth face mask, it must be breathable, which means air permeable, comfortable in terms of feel and smell and upon all the fabric must have the capability to protect the wearer from infestation. This is corroborated by [30] 
who stated that wearing a mask over the mouth and nose which prevents inhalation of particles containing the virus can be crucial to preventing infection. The study also revealed that for cloth face masks, it is ideal to use layered fabrics made of two fibers to ensure good filtration of the particles that the mask might pick from the air or cough particles of a COVID-19 infested person. [31] affirmed that double-layered fabric masks can filter particles better than cloth masks made of a single-layered fabric. According to the Georgia Institute of Technology [32] wearing a face mask can protect oneself and others from COVID-19, but the type of material and how many fabric layers are used can significantly affect exposure risk.

However, [33] argued that the addition of extra layers of fabric for the production of cloth face masks affects breathability. According to [34] the ideal fabric mask for use by the general public should consist of three layers, where two of the three layers are water-resistant (hydrophobic) materials such as polypropylene and the third layer in contact with the face is an absorbent (hydrophilic) material such as cotton. It is recommended that, for layered fabrics, the outer layer should be made from Cotton because of its good properties of air permeability, comfort and smooth feel. However, the inner fabric could be made from Linen, Cotton-Polyester blend or Silk.

\section{Conflicts of Interest}

No potential conflict of interest was reported by the authors.

\section{References}

[1] Cennimo, D.J. (2020) What Is COVID-19. https://www.medscape.com/answers/2500114-197401/what-is-covid-19

[2] Gugnani, N. and Gugnani, S. (2020) Safety Protocols for Dental Practices in the COVID-19 Era. Evidence-Based Dentistry, 21, 56-57. https://doi.org/10.1038/s41432-020-0094-6

[3] Cowling, B.J., Ali, S.T., Ng, T.W., Tsang, T.K., Li, J.C., Fong, M.W., Leung, G.M., et al. (2020) Impact Assessment of Non-Pharmaceutical Interventions against Coronavirus Disease 2019 and Influenza in Hong Kong: An Observational Study. The Lancet Public Health, 5, e279-e288. https://doi.org/10.1016/S2468-2667(20)30090-6

[4] Department of Public Health (2020) How to Put on and Remove a Face Mask. https://www.sfcdcp.org/communicable-disease/healthy-habits/how-to-put-on-and-r emove-a-face-mask/

[5] Greenhalgh, T., Schmid, M.B., Czypionka, T., Bassler, D. and Gruer, L. (2020) Face Masks for the Public during the COVID-19 Crisis. British Medical Journal, 369, m1435. https://doi.org/10.1136/bmj.m1435

[6] Buami, E.K., Kumah, C., Vigbedor, D., Tsotorvor, R.M. and Pan, R. (2021) Comparative Study of Polypropylene Non-Woven Surgical Mask and Locally Manufactured Woven and Knitted Fabric Facial Masks. Journal of Textile Science \& Technology, 7, 131-141. https://doi.org/10.4236/jtst.2021.93011

[7] Seladi-Sculman, J. (2020) Can Face Mask Protect You from the 2019 Corona Virus? What Types, When and How to Use It. 
[8] Rossettie, S., Perry, C., Pourghaed, M. and Zumwalt, M. (2020) Effectiveness of Manufactured Surgical Masks, Respirators, and Home-Made Masks in Prevention of Respiratory Infection Due to Airborne Microorganisms. The Southwest Respiratory and Critical Care Chronicles, 8, 11-26. https://doi.org/10.12746/swrccc.v8i34.675

[9] Mawkhlieng, U. and Majumdar, A. (2021) Waste Management of Medical Personal Protective Equipment and Facemasks: Challenges during and Post COVID-19 Pandemic. In: COVID-19, Springer, Singapore, 37-60.

https://doi.org/10.1007/978-981-16-3856-5 2

[10] Karim, N., Afroj, S., Lloyd, K., Oaten, L.C., Andreeva, D.V., Carr, C., Novoselov, K.S., et al. (2020) Sustainable Personal Protective Clothing for Healthcare Applications: A Review. ACS Nano, 14, 12313-12340.

https://doi.org/10.1021/acsnano.0c05537

[11] Jain, M., Kim, S.T., Xu, C., Li, H. and Rose, G. (2020) Efficacy and Use of Cloth Masks: A Scoping Review. Cureus, 12, e10423. https://doi.org/10.7759/cureus.10423

[12] Trade Industry \& Competition, Republic of South Africa (2020) Recommended Guidelines for Wearing of Face Masks.

[13] Zhao, M., Liao, L., Xiao, W., Yu, X., Wang, H., Wang, Q. and Cui, Y. (2020) Household Materials Selection for Homemade Cloth Face Coverings and Their Filtration Efficiency Enhancement with Triboelectric Charging. Nano Letters, 20, 5544-5552. https://doi.org/10.1021/acs.nanolett.0c02211

[14] Rawal, A. (2020) Multi-Layered Masks to Combat COVID-19. The Indian Journal of Medical Research, 152, 9-11. https://doi.org/10.4103/ijmr.IJMR 270920

[15] FDA (2020) FDA Recommendations for Home-Made Face Masks. https://citinewsroom.com/2020/04/fda-recommendations-for-homemade-face-mas $\underline{\mathrm{ks} /}$

[16] Aydin, O., Emon, B., Cheng, S., Hong, L., Chamorro, L.P. and Saif, M.T.A. (2020) Performance of Fabrics for Home-Made Masks against the Spread of COVID-19 through Droplets: A Quantitative Mechanistic Study. Extreme Mechanics Letters, 40, Article ID: 100924. https://doi.org/10.1016/j.eml.2020.100924

[17] Wang, D., Ji, M. and Wang, C. (2014) Factory Kn95 N95 Non-Woven Melt Blown Fabric Disposable Face Mask. Brazilian Journal of Chemical Engineering, 31, 9-18. https://doi.org/10.1590/S0104-66322014000100002

[18] American Chemical Society (2020) The Best Material for Home-Made Face Masks May Be a Combination of Two Fabrics. Science News.

[19] Asadi, S., Cappa, C.D., Barreda, S., Wexler, A.S., Bouvier, N.M. and Ristenpart, W.D. (2020) Efficacy of Masks and Face Coverings in Controlling outward Aerosol Particle Emission from Expiratory Activities. Scientific Reports, 10, Article No. 15665. https://doi.org/10.1038/s41598-020-72798-7

[20] Ghana Statistical Service (2020) Ghana's Population by Region. https://www.statsghana.gov.gh

[21] Textile School (2019) Natural Cellulose Fibers-Nature's Own Fibers. https://www.textileschool.com/379/natural-cellulose-fibres-natures-own-fibres

[22] Firgo, H., Schuster, K.C., Suchomel, F., Männer, J., Burrow, T. and Rous, M.A. (2006) The Functional Properties of TENCEL ${ }^{\circledR}-\mathrm{A}$ Current Update. Lenzinger Berichte, 85, 22-30.

[23] Dipanwita, R. (2020) Different Types of Fabrics Used in Making Face Mask. Online Clothing Study. 
[24] Vedantu Master Classes (2020) Animal Fiber. Learn Live Online.

[25] Crenshaw, M. (2020) 10 Polyester Face Masks That Have Some of the Most Effective Protections. Fairchild Publishing, New York.

[26] Hohman, M. (2020) What Type of Fiber Is Best for Face Masks. https://www.today.com/style

[27] Songer, J. and Rizvi, S. (2020) Mask Fabrics: Introduction to Fibers and Fabrics. https://makermask.org/mask-fabrics-101-introduction-to-fibers-and-fabrics/

[28] Kubaş, A., Yilmaz, F., Aktaş, Y. and Metin, N. (2005) Analysis of Visitor Decision Making System When Visiting Natural Recreation Sites by Multinomial Logit Model. Quality and Quantity, 39, 615-623. https://doi.org/10.1007/s11135-005-3151-5

[29] Louri, H., Papanastassiou, M. and Lantouris, J. (2000) FDI in the EU Periphery: A Multinomial Logit Analysis of Greek Firm Strategies. Regional Studies, 34, 419-427. https://doi.org/10.1080/00343400050058675

[30] Gasparini, A. (2020) These Are the Best Fabrics to Use for Your Cloth Masks According to Research.

[31] O’Kelly, E. (2020) What Fabric Should You Make Your Face Mask from? The Conversation Africa Inc., Melbourne.

[32] Anne, W.S. (2020) Covid-19 Mask Study Finds Layering, Material Choice Matter. Georgia Institute of Technology, Atlanta.

[33] Clase, C., De-Lannoy, C., Larrero, J., Pecoits-Flho, R. and Laengert, S. (2021) Are Two Cloth Masks Netter than One for Preventing the Spread of COVID-19. The Conversation Africa Inc., Melbourne.

[34] Songer, J. (2021) World Health Organization Guidance on Face Masks Change. World Health Organization, Geneva. 